\title{
Improvement in Medication Adherence Using TV Programmes as Reminders
}

\author{
Saibal Kumar Saha, Sikkim Manipal Institute of Technology, Sikkim Manipal University, India \\ iD https://orcid.org/0000-0002-7842-698X \\ Anindita Adhikary, Sikkim Manipal Institute of Technology, Sikkim Manipal University, India \\ Ajeya Jha, Sikkim Manipal Institute of Technology, Sikkim Manipal University, India \\ iD https://orcid.org/0000-0003-0491-5008
}

Vijay Kumar Mehta, Sikkim Manipal Institute of Medical Sciences, Sikkim Manipal University, India

\begin{abstract}
According to $\mathrm{WHO}$, only $50 \%$ of patients adhere to chronic therapy. The problem of non-adherence has persisted over decades. Over 197 million Indian households have TV sets, and on average Indians spend 3 hours, 44 minutes watching television. A TV programme is used as intervention by patients to improve medication adherence rates. The objective of the research is to find the effect of TV programmes as a form of reminder in improving medication adherence. With the help of a structured questionnaire, the information about medication adherence behaviour was obtained from patients suffering from different types of diseases in the state of Sikkim, India. It has been found that when patients use TV programmes as a form of reminder, the odds of missing the medication consciously reduces by $45.9 \%$. At a personal level, the probability that a person will not miss the time of medication is $42.3 \%$ higher compared to when it is not used, and if the total population is considered, $15.6 \%$ fewer people would not be missing the medication at all when the reminder is used.
\end{abstract}

\section{KEYWORDS}

Adherence, Medication Medication Regime, Odds Ratios, Patient Beliefs, Relative Risk, Reminder, Risk Difference, Sikkim, TV Programme

\section{INTRODUCTION}

Medication adherence is defined as "the degree to which a person's behaviour corresponds to the recommendations made by a health care provider" (Sabaté et al., 2003). WHO has reported that only $50 \%$ of people adhere to their chronic therapy (WHO I ADHERENCE TO LONG-TERM THERAPIES: EVIDENCE FOR ACTION, 2015). Medication non-adherence is associated with increased health risks and treatment costs (Gu et al., 2020). As of 2018 4.3\% of hospital admissions in Asia, Europe, Australia and North America were due to non-adherence (Mongkhon et al., 2018). Demographic characteristics and social factors (Liddelow et al., 2020) have been associated with medication adherence. Males have been reported to be more adherent than females (Chen et al., 2014; Manteuffel 
et al., 2014). The study conducted in Taiwan associates low causative ascription to culture, lesser symptoms and more ascription to risk factors for males and more causative ascription to balance and risk factors, illness coherence and less personal control for females (Chen et al., 2014). One study reports this number to be 4\% (Eindhoven et al., 2018). Self-reporting (Al-Ganmi et al., 2020), pill count (Saberi et al., 2020) and direct observation (Hawkshead \& Krousel-Wood, 2007) are some of the techniques used to measure adherence. With the analytic method of ratios, effect of interventions on diseases (Foroutan et al., 2020; Hu et al., 2020; Meco et al., 2019) has been studied. In this study, with the help of probability and ratio analysis the effect of TV programme as a form of reminder in addressing the barriers of medication adherence has been studied.

\section{LITERATURE REVIEW}

Treatment of chronic diseases require long-term therapies. Medication non-adherence is a hurdle for obtaining the desired results in such treatment processes (Alhazami et al., 2020). Non-adherence is a complex set of behaviours which may be due to intentional or unintentional causes (Chan et al., 2020). Patient's inability to adhere due to lack of resources is called unintentional non-adherence. When patient decides not to follow the regime, it is called intentional non-adherence. Patients may resort to non-adherent behaviour at any stage of the medication process (Hatah et al., 2020).

Studies report that medication non-adherence is a worldwide phenomenon (Hatah et al., 2020). In developed countries non-adherence is reported to be 50\% (Institute, 2009). It is estimated that in United States the rate of non-adherence for chronic patients range between $30 \%$ to $50 \%$ while for developing countries like Gambia and China the rates are $73 \%$ and 54\% respectively (Sabaté et al., 2001). Studies conducted in Malaysia reported adherence rate to be 53\% (Sufiza Ahmad et al., 2013) and 53.4\% (Ramli et al., 2012) among patients suffering from diabetes and hypertension. Studies conducted in Europe reported non-adherence to be $60.24 \%$ for antiosteoporotics, $55.63 \%$ for antihyperlipidemics and $46.80 \%$ for oral antidiabetics (Menditto et al., 2018).

WHO has classified the causes of non-adherence as "socioeconomic factors, health care and system-related factors, therapy-related factors, condition-related factors and patient-related factors" (Putignano et al., 2017). Medication non-adherence is often related with failure on the part of patient to comply with the medication regime as prescribed by physician, but other factors like access to healthcare facilities, instructions related to drug administration, patient physician relationship, side effects, severity of the disease, dose complexity, beliefs, forgetfulness, adverse events and communication (Kardas et al., 2013) (Scala et al., 2016). Studies suggest that medication nonadherence is affected by multiple factors and these factors are related to each other (Menditto et al., 2020). Several interventions have been designed to address the problem of medication non-adherence, which have shown varying degree of success rates.

Side effect of many types of medicine causes itching (Okumus et al., 2020) and formation of rashes in the skin (Aruta et al., 2020). These have been associated with medication non-adherence (Carpenter et al., 2020). Studies have reported taking medicine later 4.8\% (Ma et al., 2019) is associated with medication non adherence (Garaix et al., 2018). While many patients consciously miss their medication (Sharkness \& Snow, 1992; Webb et al., 2001). Running out of medicine (Hill-Briggs et al., 2005) has been reported in many studies as a form of medication non-adherence: $13.4 \%$ (Tsega et al., 2015), 35\% (Martin et al., 2010). A study on chronic obstructive pulmonary disease and asthma patients reports stop/miss medication was largely when patients felt better (64.81\%) (Fugate et al., n.d.). Taking medication as per the time prescribed (Harris et al., 2019) by physician is crucial for recovery of patient. Studies report that activities like eating breakfast (Wagner \& Ryan, 2004), watching TV Programme (Sorensen et al., 1998) which are structured and routinized are important predictors of medication adherence. India, with a population 1.37 billion (Ghosh, 2020) people has 298 million households, of which 197 has a TV set (Number of Homes with TV Sets Grows by $7.5 \%$ 
to 197 Million, Says BARC - The Financial Express, n.d.). It is reported that Indians on an average spend 3 hours, 44 minutes watching television (Indians Are Watching TV for 3 Hour 44 Minutes Every Day: BARC India - The Economic Times, n.d.). Hence, TV programme as intervention is often used by people to adhere to medication regime (Heylen et al., 2020).

\section{METHODOLOGY}

By clustered sampling technique, 509 patients suffering from different types of diseases in Sikkim, India were interviewed and asked whether they agree to the following factors or not (Yes or No).

1. Continuing medication is important even if it leads to formation of rashes in the skin or causes itching.

2. Taking medicine later even after missing it.

3. Running out of medicine.

4. Missing the medication consciously.

5. Not missing the medication at all.

6. Not missing the time of medication.

The respondents were asked (Yes or No) whether TV programme was used by them as a form of reminder to take medication. The responses were tabulated as shown in Table 1 .

In Table $1, \mathrm{w}, \mathrm{x}, \mathrm{y}$ and $\mathrm{z}$ are number of responses.

The probability of positive response of the factor when TV programme is used as reminder is calculated as:

$$
\hat{p}_{\text {TV Programme }}=\frac{w}{(w+x)}
$$

The probability of positive response of the factor when reminder is not used is calculated as:

$$
\hat{p}_{\text {no reminder }}=\frac{y}{(y+z)}
$$

The other formulae used are as follows (Hancock \& Kent, 2016):

1. Risk Difference: $\widehat{R D}=\hat{p}_{\text {TV Programme }}-\hat{p}_{\text {no reminder }}$ :

a. Standard error:

Table 1. Response tabulation format

\begin{tabular}{|l|l|l|}
\hline & TV Programme used as reminder & \multicolumn{1}{|c|}{ Reminder not used } \\
\hline Positive response of the factor & w & $y$ \\
\hline Negative response of the factor & $\mathrm{x}$ & $\mathrm{z}$ \\
\hline Total & $\mathrm{w}+\mathrm{x}$ & $\mathrm{y}+\mathrm{z}$ \\
\hline
\end{tabular}


$\widehat{S E}\left(\hat{p}_{\text {TV Programme }}-\hat{p}_{\text {no reminder }}\right)=\sqrt{\frac{\left(\hat{p}_{\text {TV Programme }}\right)\left(1-\hat{p}_{\text {TV Programme }}\right)}{(w+x)}+\frac{\left(\hat{p}_{\text {no reminder }}\right)\left(1-\hat{p}_{\text {no reminder }}\right)}{(y+z)}}$

b. $95 \%$ confidence interval (CI):

$\left(\hat{p}_{\text {TV Programme }}-\hat{p}_{\text {no reminder }}\right) \pm 2 \widehat{S E}\left(\hat{p}_{\text {TV Programme }}-\hat{p}_{\text {no reminder }}\right)$

2. Relative Risk: $\widehat{R R}=\frac{\hat{p}_{\text {TV Programme }}}{\hat{p}_{\text {no reminder }}}$ :

a. Log of $\widehat{R R}$ is calculated as $\ln \widehat{(R R})$;

b. Standard error:

$\widehat{S E}(\ln (\widehat{R R}))=\sqrt{\frac{1}{w}-\frac{1}{(w+y)}+\frac{1}{x}-\frac{1}{(x+z)}}$

c. $95 \%$ confidence interval $(\mathrm{CI}): \ln (\widehat{R R}) \pm 2 \widehat{S E}(\ln (\widehat{R R}))$, then anti-log of the values were taken;

3. Odds Ratio:

$$
\widehat{O R}=\frac{\frac{\hat{p}_{\text {TV Programme }}}{\left(1-\hat{p}_{\text {TV Programme }}\right)}}{\frac{\hat{p}_{\text {no reminder }}}{\left(1-\hat{p}_{\text {no reminder }}\right)}}
$$

a. Log of $\widehat{O R}$ is calculated as $\ln (\widehat{O R})$;

b. Standard error:

$$
\widehat{S E}(\ln (\widehat{O R}))=\sqrt{\frac{1}{w}+\frac{1}{x}+\frac{1}{y}+\frac{1}{z}}
$$

c. $\quad 95 \%$ confidence interval $(\mathrm{CI}): \ln (\widehat{O R}) \pm 2 \widehat{S E}(\ln (\widehat{O R}))$, then anti-log of the values were taken. 
Since both the values at $95 \%$ confidence interval has the same sign ( + or -) it can be said that results were due to use of TV Programme as reminder and not by chance.

\section{ANALYSIS AND DISCUSSION}

Responses obtained were analysed and their implications are discussed as follows.

Continuing medication is important even if it leads to formation of rashes in the skin or causes itching.

$\widehat{R D}=18.3 \%$ means that when TV programme is used as a reminder there is $18.3 \%$ absolute probability of increase in "continuing medication even if it leads to formation of rashes in the skin or causes itching" compared to when it is not used. CI 95\% (9.6\%, 27.0\%) means that after accounting for "sampling variability" the effect of TV programme as reminder on "continuing medication even if it leads to formation of rashes in the skin or causes itching" could increase between $9.6 \%$ to $27.0 \%$. $\widehat{R R}=50.5 \%$ means that when a person uses TV programme a form of reminder he will "continue medication even if it leads to formation of rashes in the skin or causes itching" is $50.5 \%$ higher compared to when it is not used. CI 95\% (23.0\%, 84.2\%) means that the assessments in probability may increase by as low as $23.0 \%$ to as high as $84.2 \%$. $\widehat{O R}=111.0 \%$ means that people who uses TV programme as a form of reminder has $111.0 \%$ greater odds of "continuing medication even if it leads to formation of rashes in the skin or causes itching" compared to when they do not use. CI 95\% $(46.8 \%, 203.2 \%)$ means that the assessments in probability odds may increase by as low as $46.8 \%$ to as high as $203.2 \%$.

\section{TAKING MEDICINE LATER EVEN AFTER MISSING IT}

$\widehat{R D}=9.1 \%$ means that when TV programme is used as a reminder there is $9.1 \%$ absolute probability of increase in "taking medicine later even after missing it" compared to when it is not used. CI 95\% $(0.8 \%, 17.4 \%)$ means that after accounting for "sampling variability" the effect of TV programme as reminder on "taking medicine later even after missing it" could increase between $0.8 \%$ to $17.4 \%$. $\widehat{R R}=51.0 \%$ means when a person uses TV programme a form of reminder he will "take medicine later even after missing it" is $51.0 \%$ higher compared to when it is not. CI 95\% $(6.1 \%, 114.9 \%)$ means that the assessments in probability may increase by as low as $6.1 \%$ to as high as $114.9 \%$. $\widehat{O R}=$ $69.7 \%$ means that people who uses TV programme as a form of reminder has $69.7 \%$ greater odds of

Table 2. $\widehat{R D}, \widehat{R R}, \widehat{O R}$ or rashes in the skin or causing itching

\begin{tabular}{|c|c|c|c|}
\hline \multirow[b]{2}{*}{ Parameter } & \multirow[b]{2}{*}{ Parameter \% } & \multicolumn{2}{|c|}{ CI 95\% } \\
\hline & & Parameter - $2 \widehat{S E}$ & Parameter $+2 \widehat{S E}$ \\
\hline$\widehat{R D}$ & $18.3 \%$ & $9.6 \%$ & $27.0 \%$ \\
\hline$\widehat{R R}$ & $50.5 \%$ & $23.0 \%$ & $84.2 \%$ \\
\hline$\widehat{O R}$ & $111.0 \%$ & $46.8 \%$ & $203.2 \%$ \\
\hline
\end{tabular}


Table 3. $\widehat{R D}, \widehat{R R}, \widehat{O R}$ making medication later

\begin{tabular}{|c|c|c|c|}
\hline \multirow[b]{2}{*}{ Parameter } & \multirow[b]{2}{*}{ Parameter \% } & \multicolumn{2}{|c|}{ CI 95\% } \\
\hline & & Parameter-2 $\widehat{S E}$ & Parameter $+2 \widehat{S E}$ \\
\hline$\widehat{R D}$ & $9.1 \%$ & $0.8 \%$ & $17.4 \%$ \\
\hline$\widehat{R R}$ & $51.0 \%$ & $6.1 \%$ & $114.9 \%$ \\
\hline$\widehat{O R}$ & $69.7 \%$ & $7.0 \%$ & $169.2 \%$ \\
\hline
\end{tabular}

“taking medicine later even after missing it" compared to when they do not. CI 95\% (7.0\%, 169.2\%) means that the assessments in probability odds may increase by as low as $7.0 \%$ to as high as $169.2 \%$.

\section{RUNNING OUT OF MEDICINE}

$\widehat{R D}=-12.0 \%$ means that when TV programme is used as a reminder there is $12.0 \%$ absolute probability of decrease in "running out of medicine" compared to when it is not used. CI 95\% (-20.7\%, $-3.3 \%$ ) means that after accounting for "sampling variability" the effect of TV programme as reminder on "running out of medicine" could decrease between $20.7 \%$ to $3.3 \%$. $\widehat{R R}=19.1 \%$ means when a person uses TV programme a form of reminder he will "run out of medicine" is $19.1 \%$ lower compared to when it is not used. CI $95 \%(30.8 \%, 5.4 \%)$ means that the assessments in probability may decrease by as low as $5.4 \%$ to as high as $30.8 \%$. $\widehat{O R}=38.9 \%$ means that people who uses TV programme as a form of reminder has $38.9 \%$ lower odds of "running out of medicine" compared to when they do not. CI 95\% (57.4\%, 12.3\%) means that the assessments in probability odds may decrease by as low as $12.3 \%$ to as high as $57.4 \%$.

Table 4. $\widehat{\boldsymbol{R D}}, \widehat{\boldsymbol{R R}}, \widehat{\boldsymbol{O R}}$ or running out of medicine

\begin{tabular}{|c|c|c|c|}
\hline \multirow[b]{2}{*}{ Parameter } & \multirow[b]{2}{*}{ Parameter \% } & \multicolumn{2}{|c|}{ CI 95\% } \\
\hline & & Parameter - $2 \widehat{S E}$ & Parameter $+2 \widehat{S E}$ \\
\hline$R D$ & $-12.0 \%$ & $-20.7 \%$ & $-3.3 \%$ \\
\hline$\widehat{R R}$ & $19.1 \%$ & $30.8 \%$ & $5.4 \%$ \\
\hline$\widehat{O R}$ & $38.9 \%$ & $57.4 \%$ & $12.3 \%$ \\
\hline
\end{tabular}




\section{MISSING THE MEDICATION CONSCIOUSLY}

$\widehat{R D}=-14.4 \%$ means that when TV programme is used as a reminder there is $14.4 \%$ absolute probability of decrease in "missing the medication consciously" compared to when it is not. CI 95\% $(-22.9 \%,-5.9 \%)$ means that after accounting for "sampling variability" the effect of TV programme as reminder on "missing the medication consciously" could decrease between $22.9 \%$ to $5.9 \%$. $\widehat{R R}$ $=20.9 \%$ means when a person uses TV programme a form of reminder he will "miss the medication consciously" is $20.9 \%$ lower compared to when it is not used. CI $95 \%(31.4 \%, 8.8 \%)$ means that the assessments in probability may decrease by as low as $8.8 \%$ to as high as $31.4 \%$. $\widehat{O R}=45.9 \%$ means that people who uses TV programme as a form of reminder has $45.9 \%$ lower odds of "missing the medication consciously" compared to when they do not. CI $95 \%(62.6 \%, 21.7 \%)$ means that the assessments in probability odds may decrease by as low as $21.7 \%$ to as high as $62.6 \%$.

\section{NOT MISSING THE MEDICATION AT ALL}

$\widehat{R D}=-15.6 \%$ means that when TV programme is used as a reminder there is $15.6 \%$ absolute probability of decrease in "not missing the medication at all" compared to when it is not. CI 95\% $(-23.7 \%,-7.5 \%)$ means that after accounting for "sampling variability" the effect of TV programme as reminder on "not missing the medication at all" could decrease between $23.7 \%$ to $7.5 \%$. $\widehat{R R}=$ $20.3 \%$ means when a person uses TV programme a form of reminder he will "not miss the medication at all" is $20.3 \%$ lower compared to when it is not used. CI 95\% $(29.4 \%, 10.0 \%)$ means that the estimates in probability may decrease by as low as $10.0 \%$ to as high as $29.4 \%$. $\widehat{O R}=52.3 \%$ means that people who uses TV programme as a form of reminder has 52.3\% lower odds of "not missing the medication at all" compared to when they do not. CI 95\% (67.8\%, 29.4\%) means that the assessments in probability odds may decrease by as low as $29.4 \%$ to as high as $67.8 \%$.

\section{NOT MISSING THE TIME OF MEDICATION}

$\widehat{R D}=10.6 \%$ means that when TV programme is used as a reminder there is $10.6 \%$ absolute probability of increase in "not missing the time of medication" compared to when it is not used. CI 95\% (1.5\%, $19.6 \%$ ) means that after accounting for "sampling variability" the effect of TV programme as reminder on "not missing the time of medication" could increase between $1.5 \%$ to $19.6 \%$. $\widehat{R R}=42.3 \%$ means when a person uses TV programme a form of reminder he will "not miss the time of medication" is

Table 5. $\widehat{\boldsymbol{R D}}, \widehat{\boldsymbol{R R}}, \widehat{\boldsymbol{O R}}$ or missing the medication consciously

\begin{tabular}{|c|c|c|c|}
\hline \multirow{2}{*}{ Parameter } & \multirow[b]{2}{*}{ Parameter \% } & \multicolumn{2}{|c|}{ CI 95\% } \\
\hline & & Parameter - $2 \widehat{S E}$ & Parameter $+2 \widehat{S E}$ \\
\hline$R D$ & $-14.4 \%$ & $-22.9 \%$ & $-5.9 \%$ \\
\hline$R R$ & $20.9 \%$ & $31.4 \%$ & $8.8 \%$ \\
\hline$\widehat{O R}$ & $45.9 \%$ & $62.6 \%$ & $21.7 \%$ \\
\hline
\end{tabular}


Table 6. $\widehat{R D}, \widehat{R R}, \widehat{O R}$ or not missing the medication at all

\begin{tabular}{|c|c|c|c|}
\hline \multirow[b]{2}{*}{ Parameter } & \multirow[b]{2}{*}{ Parameter \% } & \multicolumn{2}{|c|}{ CI 95\% } \\
\hline & & Parameter - $2 \widehat{S E}$ & Parameter $+2 \widehat{S E}$ \\
\hline$\widehat{R D}$ & $-15.6 \%$ & $-23.7 \%$ & $-7.5 \%$ \\
\hline$\widehat{R R}$ & $20.3 \%$ & $29.4 \%$ & $10.0 \%$ \\
\hline$\widehat{O R}$ & $52.3 \%$ & $67.8 \%$ & $29.4 \%$ \\
\hline
\end{tabular}

$42.3 \%$ higher compared to when it is not used. CI 95\% (6.9\%, 89.4\%) means that the assessments in probability may increase by as low as $6.9 \%$ to as high as $89.4 \%$. $\widehat{O R}=65.6 \%$ means that people who uses TV programme as a form of reminder has $65.6 \%$ greater odds of "not missing the time of medication" compared to when they do not. CI 95\% $(8.8 \%, 152.1 \%)$ means that the assessments in probability odds may increase by as low as $8.8 \%$ to as high as $152.1 \%$.

\section{CONCLUSION}

The $\widehat{R D}$ may not appear to be very high, but when the population numbers are used the number of people affected by it are significantly large. $\widehat{R D}=18.3 \%$ implies that for every 1000 people, 183 more people would be "continuing medication even if it leads to formation of rashes in the skin or causes itching" when TV programme is used as reminder. This number could be as low as 96 to as large as $270 . \widehat{R D}=9.1 \%$ implies that for every 1000 people, 91 more people would be "taking medicine later even after missing it" when TV programme is used as reminder. This number could be as low as 8 to as large as $174 . \widehat{R D}=-12.0 \%$ implies that for every 1000 people, 120 less people would be "running out of medicine" when TV programme is used as reminder. This number could be as low as 33 to as large as 207. $\widehat{R D}=-14.4 \%$ implies that for every 1000 people, 144 less people would be "missing the medication consciously" when TV programme is used as reminder. This number could be as low as 59 to as large as $229 . \widehat{R D}=-15.6 \%$ implies that for every 1000 people,

Table 7. $\widehat{R D}, \widehat{R R}, \widehat{O R}$ or not missing the time of medication

\begin{tabular}{|c|c|c|c|}
\hline \multirow[b]{2}{*}{ Parameter } & \multirow[b]{2}{*}{ Parameter \% } & \multicolumn{2}{|c|}{ CI 95\% } \\
\hline & & Parameter-2 $\widehat{S E}$ & Parameter $+2 \widehat{S E}$ \\
\hline$R D$ & $10.6 \%$ & $1.5 \%$ & $19.6 \%$ \\
\hline$\widehat{R R}$ & $42.3 \%$ & $6.9 \%$ & $89.4 \%$ \\
\hline$\widehat{O R}$ & $65.6 \%$ & $8.8 \%$ & $152.1 \%$ \\
\hline
\end{tabular}


156 less people would not be "missing the medication at all" when TV programme is used as reminder.

This number could be as low as 75 to as large as $237 . \widehat{R D}=10.6 \%$ implies that for every 1000 people, 106 more people would "not be missing the time of medication" when TV programme is used as reminder. This number could be as low as 15 to as large as 196.

$\mathrm{TV}$, being a very common item in almost every household in Sikkim and patients who spend considerable amount of time watching different types of programmes may use a particular programme's commencement or ending time to take the prescribed medication. It can act as a reminder and help to increase adherence. Studies have found that odds of adherence increase by 3\% (Ramli et al., 2012) with increase in age, with increase in adherence there is decrease in hospitalization by $33 \%$ (Kim et al., 2016) and odds reduce by $15 \%$ (Lage \& Hassan, 2009).

\section{Funding}

This research was funded by All India Council for Technical Education (AICTE), India under Research Promotion Scheme for North Eastern Region (RPS-NER) for the grant entitled "Impact of Active Reminders on Medication Adherence" as per letter No 8-104/RIFD/RPS-NER/Policy-1/2019-19 dated 14 March 2019. 


\section{REFERENCES}

Al-Ganmi, A. H. A., Alotaibi, A., Gholizadeh, L., \& Perry, L. (2020). Medication adherence and predictive factors in patients with cardiovascular disease: A cross-sectional study. Nursing \& Health Sciences. 10.1111/nhs.12681

Alhazami, M., Pontinha, V. M., Patterson, J. A., \& Holdford, D. A. (2020). Medication adherence trajectories: A systematic literature review. In Journal of Managed Care and Specialty Pharmacy (Vol. 26, Issue 9, pp. 1138-1152). Academy of Managed Care Pharmacy (AMCP). doi:10.18553/ jmcp.2020.26.9.1138

Aruta, F., Iovino, A., Costa, C., Manganelli, F., \& Iodice, R. (2020). Lichenoid rash: A new side effect of oral Cladribine. Multiple Sclerosis and Related Disorders, 41, 102023. doi:10.1016/j.msard.2020.102023 PMID:32146431

Carpenter, B. S., Hanass-Hancock, J., \& Myezwa, H. (2020). Looking at antiretroviral adherence through a disability lens: A cross-sectional analysis of the intersection of disability, adherence, and health status. Disability and Rehabilitation, 42(6), 806-813. doi:10.1080/09638288.2018.1510048 PMID:30616436

Chan, A. H. Y., Horne, R., Hankins, M., \& Chisari, C. (2020). The Medication Adherence Report Scale: A measurement tool for eliciting patients' reports of nonadherence. British Journal of Clinical Pharmacology, 86(7), 1281-1288. doi:10.1111/bcp.14193 PMID:31823381

Chen, S.-L., Lee, W.-L., Liang, T., \& Liao, I.-C. (2014). Factors associated with gender differences in medication adherence: A longitudinal study. Journal of Advanced Nursing, 70(9), 2031-2040. doi:10.1111/jan.12361 PMID:24506542

Eindhoven, D. C., Hilt, A. D., Zwaan, T. C., Schalij, M. J., \& Borleffs, C. J. W. (2018). Age and gender differences in medical adherence after myocardial infarction: Women do not receive optimal treatment - The Netherlands claims database. European Journal of Preventive Cardiology, 25(2), 181-189. doi:10.1177/2047487317744363 PMID:29164916

Foroutan, F., Iorio, A., Thabane, L., \& Guyatt, G. (2020). Calculation of absolute risk for important outcomes in patients with and without a prognostic factor of interest. Journal of Clinical Epidemiology, 117, 46-51. doi:10.1016/j.jclinepi.2019.08.012 PMID:31589954

Fugate, A. R., Kadam, A. M., Ganachari, M. S., Ajay, M., \& Fugate, R. (2015, July 04). Prospective Study of Medication Adherence Pattern in Chronic Obstructive Pulmonary Disease and Asthma Patient's in Tertiary Care teaching Hospital. Indian Journal of Pharmacy Practice, 8(2), 78-83. Advance online publication. doi:10.5530/ ijopp.8.2.6

Garaix, F., Stern, M., Lamy, F. X., Dubel, L., \& Kamar, N. (2018). Tacrolimus Granules for Oral Suspension as Post-Transplant Immunosuppression in Routine Medical Practice in France: The OPTIMOD Study. Annals of Transplantation, 23, 561-571. doi:10.12659/AOT.908522 PMID:30093607

Ghosh, S. K. (2020). Circular Economy in India. In Circular Economy: Global Perspective (pp. 157-185). Springer Singapore. doi:10.1007/978-981-15-1052-6_9

Gu, Y., Zalkikar, A., Kelly, L., Daly, K., \& Ward, T. E. (2020). Predicting Injectable Medication Adherence via a Smart Sharps Bin and Machine Learning. https://arxiv.org/abs/2004.01144

Hancock, M., \& Kent, P. (2016). Interpretation of dichotomous outcomes: Risk, odds, risk ratios, odds ratios and number needed to treat. In Journal of Physiotherapy (Vol. 62, Issue 3, pp. 172-174). Australian Physiotherapy Association. doi:10.1016/j.jphys.2016.02.016

Harris, M., Fry, M., \& Fitzpatrick, L. (2019). A clinical process redesign project to improve outcomes and reduce care variance for people with Parkinson's disease. Australasian Emergency Care, 22(2), 107-112. doi:10.1016/j. auec.2019.02.001 PMID:31042525

Hatah, E., Rahim, N., Makmor-Bakry, M., Mohamed Shah, N., Mohamad, N., Ahmad, M., Haron, N. H., Sze Hwe, C., Tan Meng Wah, A., Hassan, F., Shaik Rahmat, S., Robert, S. A., \& Abdullah, N. (2020). Development and validation of Malaysia Medication Adherence Assessment Tool (MyMAAT) for diabetic patients. PLoS One, 15(11), e0241909. doi:10.1371/journal.pone.0241909 PMID:33157549 
Hawkshead, J., \& Krousel-Wood, M. A. (2007). Techniques for measuring medication adherence in hypertensive patients in outpatient settings: Advantages and limitations. In Disease Management and Health Outcomes (Vol. 15, Issue 2, pp. 109-118). Springer. doi:10.2165/00115677-200715020-00006

Heylen, E., Chandy, S., Shamsundar, R., Nair, S., Ravi Kumar, B. N., \& Ekstrand, M. L. (2020). Correlates of and barriers to ART adherence among adherence-challenged people living with HIV in southern India. AIDS Care, 1-8. Advance online publication. doi:10.1080/09540121.2020.1742862 PMID:32172599

Hill-Briggs, F., Gary, T. L., Bone, L. R., Hill, M. N., Levine, D. M., \& Brancati, F. L. (2005). Medication adherence and diabetes control in urban African Americans with type 2 diabetes. Health Psychology, 24(4), 349-357. doi:10.1037/0278-6133.24.4.349 PMID:16045370

Hu, D., Wang, C., \& O'Connor, A. M. (2020). A method of back-calculating the log odds ratio and standard error of the log odds ratio from the reported group-level risk of disease. PLoS One, 15(3), e0222690. doi:10.1371/ journal.pone.0222690 PMID:32126072

Indians are watching TV for 3 hour 44 minutes every day: BARC India - The Economic Times. (n.d.). Retrieved May 24, 2020, from https://economictimes.indiatimes.com/industry/media/entertainment/indians-are-watchingtv-for-3-hour-44-minutes-every-day-barc-india/articleshow/65151371.cms?from=mdr

Institute, N. E. H. (2009). Thinking outside the pillbox: a system-wide approach to improving patient medication adherence for chronic disease. New England Health Care Institute.

Kardas, P., Lewek, P., \& Matyjaszczyk, M. (2013). Determinants of patient adherence: A review of systematic reviews. Frontiers in Pharmacology, 4, 91. doi:10.3389/fphar.2013.00091 PMID:23898295

Kim, S., Shin, D. W., Yun, J. M., Hwang, Y., Park, S. K., Ko, Y. J., \& Cho, B. (2016). Medication Adherence and the Risk of Cardiovascular Mortality and Hospitalization among Patients with Newly Prescribed Antihypertensive Medications. Hypertension, 67(3), 506-512. doi:10.1161/HYPERTENSIONAHA.115.06731 PMID:26865198

Lage, M. J., \& Hassan, M. K. (2009). The relationship between antipsychotic medication adherence and patient outcomes among individuals diagnosed with bipolar disorder: A retrospective study. Annals of General Psychiatry, 8(1), 1-9. doi:10.1186/1744-859X-8-7 PMID:19226463

Liddelow, C., Mullan, B., \& Novoradovskaya, E. (2020). Exploring Medication Adherence Amongst Australian Adults Using an Extended Theory of Planned Behaviour. International Journal of Behavioral Medicine, 27(4), 1-11. doi:10.1007/s12529-020-09862-z PMID:32072454

Ma, X., Lu, Y., Yang, H., Yu, W., Hou, X., Guo, R., Wang, Y., \& Zhang, Y. (2019). Relationships between patient-related attitudinal barriers, analgesic adherence and pain relief in Chinese cancer inpatients. Supportive Care in Cancer, 1-7. doi:10.1007/s00520-019-05082-8 PMID:31701270

Manteuffel, M., Williams, S., Chen, W., Verbrugge, R. R., Pittman, D. G., \& Steinkellner, A. (2014). Influence of patient sex and gender on medication use, adherence, and prescribing alignment with guidelines. Journal of Women's Health, 23(2), 112-119. doi:10.1089/jwh.2012.3972 PMID:24206025

Martin, M. Y., Kohler, C., Kim, Y., Kratt, P., Schoenberger, Y.-M., Litaker, M. S., Prayor-Patterson, H. M., Clarke, S. J., Andrews, S., \& Pisu, M. (2010). Taking Less Than Prescribed: Medication Nonadherence and Provider-Patient Relationships in Lower-Income, Rural Minority Adults With Hypertension. Journal of Clinical Hypertension, 12(9), 706-713. doi:10.1111/j.1751-7176.2010.00321.x PMID:20883231

Meco, M., Montisci, A., Giustiniano, E., Greco, M., Pappalardo, F., Mammana, L., Panisi, P., Roscitano, C., Cirri, S., Donatelli, F., Albano, G., Mammana, L., Meco, M., Montisci, A., \& Giustiniano, E. (2019). Viscoelastic Blood Tests Use in Adult Cardiac Surgery: Meta-Analysis, Meta-Regression, and Trial Sequential Analysis. Journal of Cardiothoracic and Vascular Anesthesia, 1-9. doi:10.1053/j.jvca.2019.06.030 PMID:31445833

Menditto, E., Cahir, C., Aza-Pascual-Salcedo, M., Bruzzese, D., Poblador-Plou, B., Malo, S., Costa, E., GonzálezRubio, F., Gimeno-Miguel, A., Orlando, V., Kardas, P., \& Prados-Torres, A. (2018). Adherence to chronic medication in older populations: Application of a common protocol among three european cohorts. Patient Preference and Adherence, 12, 1975-1978. doi:10.2147/PPA.S164819 PMID:30323567

Menditto, E., Orlando, V., De Rosa, G., Minghetti, P., Musazzi, U. M., Cahir, C., Kurczewska-Michalak, M., Kardas, P., Costa, E., Lobo, J. M. S., \& Almeida, I. F. (2020). Patient centric pharmaceutical drug product design—the impact on medication adherence. In Pharmaceutics (Vol. 12, Issue 1, p. 44). MDPI AG. doi:10.3390/ pharmaceutics 12010044 
Mongkhon, P., Ashcroft, D. M., Scholfield, C. N., \& Kongkaew, C. (2018). Hospital admissions associated with medication non-adherence: A systematic review of prospective observational studies. In BMJ Quality and Safety (Vol. 27, Issue 11, pp. 902-914). BMJ Publishing Group. doi:10.1136/bmjqs-2017-007453

Number of homes with TV sets grows by 7.5\% to 197 million, says BARC - The Financial Express. (n.d.). Retrieved May 24, 2020, from https://www.financialexpress.com/industry/number-of-homes-with-tv-sets-grows-by-7-5to-197-million-says-barc/1259631/

Okumus, B., Semra Karatas, K., \& Enzel Koc, A. (2020). A serious dermatological side effect due to vortioxetine: A case report. Dusunen Adam The Journal of Psychiatry and Neurological Sciences, 33, 87-91. doi:10.14744/ DAJPNS.2019.00064

Putignano, D., Bruzzese, D., Orlando, V., Fiorentino, D., Tettamanti, A., \& Menditto, E. (2017). Differences in drug use between men and women: An Italian cross sectional study. BMC Women's Health, 17(1), 1-7. doi:10.1186/s12905-017-0424-9 PMID:28870183

Ramli, A., Ahmad, N. S., \& Paraidathathu, T. (2012). Medication adherence among hypertensive patients of primary health clinics in Malaysia. Patient Preference and Adherence, 6, 613-622. doi:10.2147/PPA.S34704 PMID:22969292

Sabaté, E. (2001). Adherence to long-term therapies: policy for action: meeting report, 4-5 June 2001. WHO.

Sabaté, E et al. (2003). Adherence to long-term therapies: evidence for action. World Health Organization.

Saberi, P., Chakravarty, D., Ming, K., Legnitto, D., Gandhi, M., Johnson, M. O., \& Neilands, T. B. (2020). Moving Antiretroviral Adherence Assessments to the Modern Era: Correlations Among Three Novel Measures of Adherence. AIDS and Behavior, 24(1), 284-290. doi:10.1007/s10461-019-02744-w PMID:31758349

Scala, D., Menditto, E., Armellino, M. F., Manguso, F., Monetti, V. M., Orlando, V., Antonino, A., Makoul, G., \& De Palma, M. (2016). Italian translation and cultural adaptation of the communication assessment tool in an outpatient surgical clinic. BMC Health Services Research, 16(1), 163. doi:10.1186/s12913-016-1411-9 PMID:27130440

Sharkness, C. M., \& Snow, D. A. (1992). The patient's view of hypertension and compliance. American Journal of Preventive Medicine, 8(3), 141-146. doi:10.1016/S0749-3797(18)30821-3 PMID:1632999

Sorensen, J. L., Mascovich, A., Wall, T. L., Dephilippis, D., Batki, S. L., \& Chesney, M. (1998). Medication adherence strategies for drug abusers with HIV/AIDS. AIDS Care, 10(3), 297-312. doi:10.1080/713612419 PMID:9828973

Sufiza Ahmad, N., Ramli, A., Islahudin, F., \& Paraidathathu, T. (2013). Medication adherence in patients with type 2 diabetes mellitus treated at primary health clinics in Malaysia. Patient Preference and Adherence, 7 , 525-530. doi:10.2147/PPA.S44698 PMID:23814461

Tsega, B., Srikanth, B. A., \& Shewamene, Z. (2015). Determinants of non-adherence to antiretroviral therapy in adult hospitalized patients, Northwest Ethiopia. Patient Preference and Adherence, 9, 373-380. doi:10.2147/ PPA.S75876 PMID:25784793

Wagner, G. J., \& Ryan, G. W. (2004). Relationship between routinization of daily behaviors and medication adherence in HIV-positive drug users. AIDS Patient Care and STDs, 18(7), 385-393. doi:10.1089/1087291041518238 PMID:15307927

Webb, D. G., Horne, R., \& Pinching, A. J. (2001). Treatment-related empowerment: Preliminary evaluation of a new measure in patients with advanced HIV disease. International Journal of STD \& AIDS, 12(2), 103-107. doi:10.1258/0956462011916875 PMID:11236098

WHO. (2015). Adherence to long-term therapies: Evidence for action. WHO. https://www.who.int/chp/ knowledge/publications/adherence_report/en/ 
Saibal Kumar Saha (UGC NET Qualified) holds a first class Master's degree in MBA and a first class Bachelor's Degree in Electronics and Communication Engineering. He has 8+ years of experience and has worked in MNCs like Cognizant Technology Solutions and Tata Aig Life. He has served National Institute of Technology - Silchar, Jyotirmoy School of Business - Kolkata, University of Technology and Management - Shillong and is presently working as Assistant Professor at Sikkim Manipal Institute of Technology - Majitar, India.

Anindita Adhikary is currently a Professor in Management, Sikkim Manipal University, India. A commerce graduate from Gauhati University, India, she happens to be an MBA from Tezpur Central University, India and was awared Doctorate by Gauhati University in 2009. Dr. Adhikary has 20 years of professional experience in academics and corporate sector. She has 65+ research publications (select papers in Scopus) to her credit and has been abroad a number of times in order to have an enriched exposure at international level. Dr. Adhikary had participated in 25 professional workshops and delivered talks as Guest Speaker at different Orientation Programmes initiated through National Productivity Council, MSME, Govt. of India and Department of Commerce. Govt. of Sikkim. Her domain of interest includes Finance and International Trade.

Vijay Kumar Mehta, MBBS, MD, PGDCA, is currently working as the Dean of Sikkim Manipal Institute of Medical Sciences. After retiring from Indian Armed Forces as Brigadier on 30th Sept. 2013 joined Sikkim Manipal Institute of Medical Sciences, Gangtok on 21st Oct. 2013 as Professor in the department of Community Medicine. Subsequently, took over as Professor and Head department of Community Medicine at Sikkim Manipal Institute of Medical Sciences, Gangtok on 1st Feb. 2014. Have more than 22 years of teaching experiences including twelve and half years as Professor and 5 years as Professor and HOD Community Medicine in SMIMS, Gangtok. 